\title{
ESTIMASI PERUBAHAN KALOR SELAMA KENAIKAN TEMPERATUR AIR DI UNTAI PRE-FASSIP-02
}

\author{
Ahmad Rofiq Sofyan ${ }^{1}$, Dedy Haryanto ${ }^{2}$, Joko Prasetyo Witoko ${ }^{2}$, Giarno ${ }^{2}$, \\ Mulya Juarsa ${ }^{2}$ \\ ${ }^{1}$ Mahasiswa Departemen Fisika, FMIPA Universitas Padjajaran Bandung \\ ${ }^{2}$ Pusat Teknologi dan Keselamatan Reaktor Nuklir - BATAN
}

\begin{abstract}
ABSTRAK
ESTIMASI PERUBAHAN KALOR SELAMA KENAIKAN TEMPERATUR AIR DI UNTAI PRE-FASSIP 02. Kecelakaan reaktor nuklir Fukushima terjadi dipicu oleh bencana alam gempa bumi dan Tsunami. Kerusakan yang terjadi pada teras reaktor akibat kegagalan sistem aktif selama proses pendinginan panas sisa peluruhan reaksi fisi berantai (residual heat). Sehingga, perlu pengembangan sistem pendingin pasif yang menggantikan sistem aktif untuk pendinginan teras ketika terjadi Stasiun Black Out (SBO) akibat pemadaman reaktor. Sistem pendingin pasif bekerja berdasarkan fenomena sirkulasi alam dari daerah panas menuju daerah dingin dalam satu untai tertutup. Sehingga untuk kebutuhan studi eksperimen terhadap pola aliran sirkulasi alam, maka dibuat fasilitas uji Untai PreFASSIP-02. Tujuan penelitian adalah untuk memperkirakan perpindahan kalor dari bagian panas menuju bagian dingin pada Untai Pre-FASSIP-02. Hasil eksperimen menunjukan bahwa proses pemanasan yang terjadi pada tabung heater semakin lama menyebabkan kenaikan temperatur air. Nilai kalor rata-rata yang diberikan oleh heater pada air untuk temperatur rata-rata $61,6^{\circ} \mathrm{C}$ selama dua jam eksperimen adalah 1264,9 kJ dan besarnya kalor yang diterima kolam ECT hanya 150, 4 kJ. Kalor tersebut memanaskan air hingga terjadi aliran sirkulasi alam yang membuat temperatur di $T_{H \text { out }}$ dan ECT meningkat meski dengan kenaikan yang kecil. Kenaikan temperatur air di $T_{H}$ out dan ECT yaitu masing-masing $35,57^{\circ} \mathrm{C}$ dan $0,07{ }^{\circ} \mathrm{C}$. Artinya perubahan kalor di dalam untai yang terjadi cukup kecil dan rugi kalor yang terjadi besar, menyebakan kenaikan temperatur air di ECT tidak akan mencapai titik didihnya.
\end{abstract}

Kata kunci: estimasi, kalor, temperatur, sirkulasi alam, sistem pasif, Pre-FASSIP-02

\section{ABSTRACT}

HEAT CHANGES ESTIMATION DURING WATER TEMPERATURE INCREASE IN THE PRE-FASSIP 02 TEST LOOP. Fukushima nuclear reactor accident was happens triggered by natural disasters of earthquake and tsunami. The damage that occurs in reactor core due to the failure of active system during cooling process of decay heat as the product of fission chain reaction. Thus, it is necessary to develop a passive cooling system that replaces the active system for core cooling when the Black Out Station (SBO) occurs due to reactor shutdown. Passive cooling systems work based on natural circulation phenomena from hot region into cold region inside a closed loop. So to the necessary of experimental studies on the natural circulation flow pattern, the loop Pre-FASSIP-02 test facility has been constructed. The purpose of experiment is to estimate heat transfer from hot region into cold region in Pre-FASSIP-02. Experimental results show that the heating process occurs inside heater tank and it caused the water temperature to increase. The average value of heat given into the water by heater for average temperature about $61.6^{\circ} \mathrm{C}$ during two hours experiment is $1264.9 \mathrm{~kJ}$ in heater tank and $150.4 \mathrm{~kJ}$ in ECT pool. The heated water caused natural circulation flow and make temperatures in $T_{H}$ out and ECT were raised, even in small quantity. The increase of water temperature in ${ }_{T H}$ out and ECT are $35.57{ }^{\circ} \mathrm{C}$ and $0.07{ }^{\circ} \mathrm{C}$ respectively. It is means that the heat changes inside the loop is small, but the heat loss is larger, causing the rise in water temperature in the ECT will not reach its boiling point.

Keywords: estimation, heat, temperature, natural circulation, passive system, Pre-FASSIP-02 


\section{PENDAHULUAN}

Kecelakaan reaktor di Fukushima terjadi pada jenis Boiling Water Reactor (BWR) yang disebabkan oleh bencana alam yaitu berupa gempa bumi dan tsunami hebat ${ }^{[1]}$. Akibat itu terjadi Tsunami dahsyat dan masuk ke dalam komplek reaktor dan merusak sistem pembangkit cadangan (secondary genset), dimana jenis PLTN Fukushima masih menggunakan pompa (active system) yang bersumber dari secondary genset ketika terjadi stasiun black out akibat konsekuensi dari reaktor shutdown. Kondisi tersebut menyebabkan proses pendinginan tidak berjalan sebagai mana mestinya, terjadi failure pada thermal management. Dimana sisa panas peluruhan dalam air di teras reaktor tidak dapat didinginkan dan menyebabkan pendidihan di teras reaktor ${ }^{[2]}$.

Alternatif lain untuk mengatasi kegagalan sistem pendingin aktif yaitu dengan memasang sistem pendingin pasif yang tidak menggunakan sumber listrik primer ${ }^{[3]}$. Sistem pendingin pasif memanfaatkan fenomena aliran sirkulasi alam (natural circulation flow) yang diperlukan untuk mengambil panas peluruhan (decay heat) setelah reaktor padam agar tidak terjadi pelelehan di teras yang menyebabkan bahan radioaktif tidak terlepas ke lingkungan ${ }^{[4]}$.

Untuk pengembangan fitur keselamatan reaktor dilakukan penelitian terkait sistem pendingin pasif, dimana suatu fasilitas uji skala kecil disebut Untai Pre-FASSIP-02 telah dibangun di Pusat Teknologi dan Keselamatan Reaktor Nuklir (PTKRN) BATAN. Fasilitas uji tersebut berguna untuk mempelajari karakterisasi fenomena sirkulasi alam pada simulasi proses pendinginan reaktor menggunakan air. Fenomena sirkulasi alam terjadi akibat kenaikan temperatur air di daerah pemanas (tangki heater) dan turunnya densitas air sehingga menyebabkan gaya apung (bouyancy force) dan bergerak ke daerah pendingin (cooler coil dan tangki pendingin). Ketika air masuk ke bagian pendingin dan mengalami pendinginan sehingga densitas air meningkat. Dikarenakan kenaikan massa air dan posisi pendingin berada di atas, maka aliran air akan bergerak ke bagian bawah akibat gaya gravitasi dan masuk ke bagian pemanas kembali, proses ini terjadi secara berulang menyebabkan terjadinya aliran sirkulasi alam ${ }^{[5]}$.

Pemahaman awal fenomena sirkulasi alam dapat dilakukan dengan mengetahui perubahan kalor yang terjadi, baik di daerah panas maupun di daerah dingin. Tujuan penelitian yang dilakukan adalah untuk mengestimasi perubahan kalor selama kenaikan temperatur air di tangki pemanas pada Untai Pre-FASSIP-02 sebagai penelitian awal untuk menentukan laju aliran sirkulasi alam.

\section{TATA KERJA}

Fasilitas penelitian yang digunakan adalah Untai Pre-FASSIP-02 (Untai Preliminary FAsilitas Simulasi SIstem Pasif 02) yang merupakan alat eksperimen untuk mempelajari fenomena aliran sirkulasi alam pada sistem pasif pendingin reaktor nuklir. Gambar 1 di bawah ini adalah diagram Untai PreFASSIP-02. 


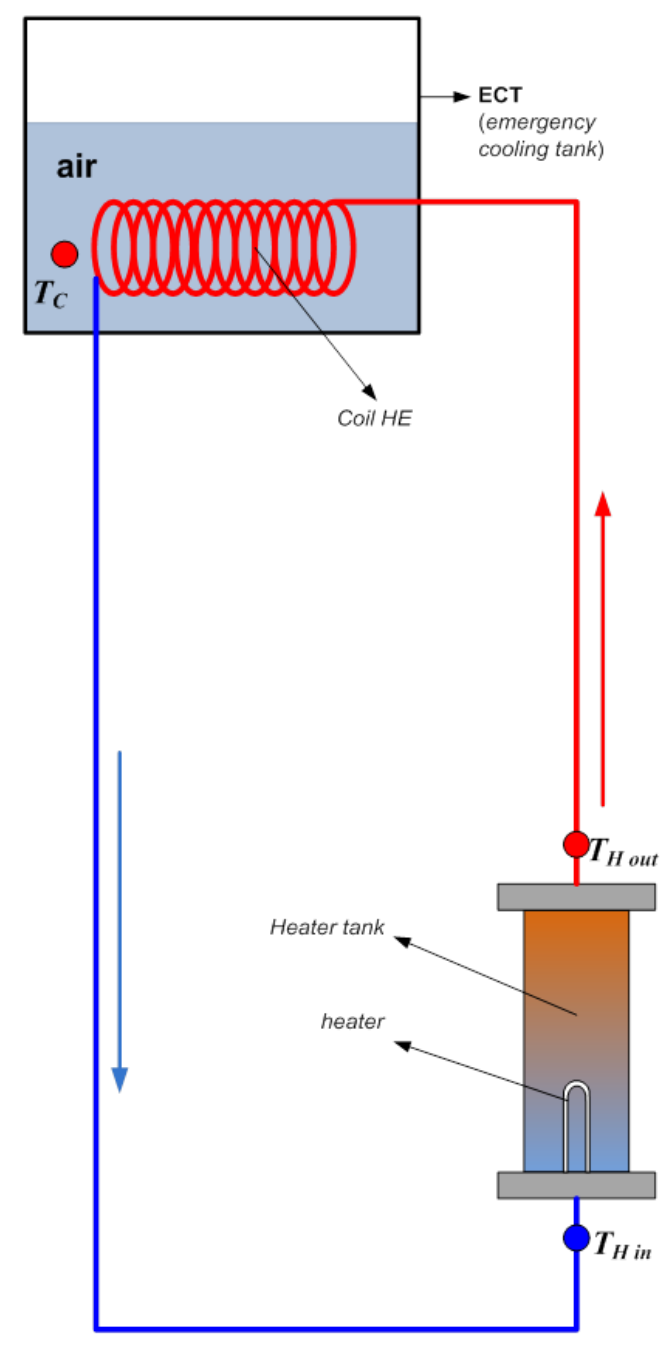

Gambar 1. Diagram Untai Pre-FASSIP-02 ${ }^{[6]}$

Komponen utama Untai Pre-FASSIP-02 berdasarkan Gambar 1 terdiri dari, tangki heater (heater tank) yang terdiri dari heater dan akrilik untuk melihat fenomena aliran di dalam tangki, kemudian coil heat exchanger (coil HE) dari material kuningan diameter 1/8 inch. Coil HE direndam di dalam tangki berisis air sebagai emergency cooling tank (ECT), sedangkan pemipaan terdiri dari pipa pyrex dan sambungan menggunakan selang.

Prosedur eksperimen dilakukan dengan tahapan-tahapan seperti yang ditunjukkan pada Gambar 2.

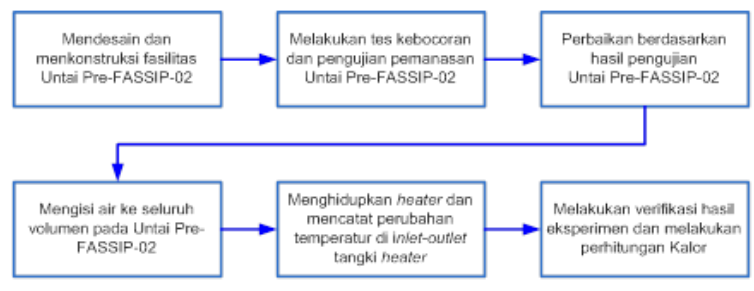

Gambar 2. Tahapan eksperimen pada Untai Pre-FASSIP-02

Setelah Untai Pre-FASSIP 02 diisi dengan air, kemudian menghidupkan heater hingga temperatur yang ditentukan dan mencatat perubahan temperatur air pada titik $T_{H}$ in, $T_{H \text { out }}$, dan $T_{C}$ seperti ditunjukkan pada Gambar 1. Kemudian data perubahan temperatur setiap 5 menit dicatat ke dalam Tabel hingga 120 menit (2 jam). Eksperimen dilakukan dengan mempertahankan temperatur air di dalam tabung tangki heater selama pemanasan sekitar $60{ }^{\circ} \mathrm{C}$ selama dua jam menggunakan sistem on -off daya heater. Kemudian, menghitung besaran kalor berdasarkan data perubahan temperatur $T_{H \text { in }}, T_{H \text { out }}$, dan $T_{C}$.

\section{HASIL DAN PEMBAHASAN}

Untuk memudahkan perhitungan estimasi perpindahan kalor yang terjadi pada Untai Pre-FASSIP-02, maka perlu diasumsikan beberapa parameter atau besaran fisika, seperti:

- $\quad$ Gelembung yang terjadi diabaikan, karena berukuran kecil dan dianggap tidak mengganggu aliran.

- $\quad$ Aliran yang terjadi dianggap steady state (tunak). 
Data temperatur $T_{H \text { in }}, T_{H \text { out }}$, dan $T_{C}$ diperoleh dari pembacaan termokopel yang dipasang di Untai Pre-FASSIP-02 dan dibaca melalui Sisitem Akuisisi Data (DAS) NI 9188. Kemudian setiap 5 menit perubahan temperatur dicatan dan dimasukan ke dalam Tabel 1. Berdasarkan tabel 1 dibuat grafik perbandingan temperatur terhadap waktu eksperimen.

Tabel 1. Data temperatur $T_{H \text { in }}, T_{H \text { out }}$, dan $T_{C}$

\begin{tabular}{|c|c|c|c|c|}
\hline No. & $\underset{\text { (menit) }}{\mathbf{t}}$ & $\begin{array}{l}?_{n m} n \\
\left({ }^{\circ} \mathrm{C}\right)\end{array}$ & $\begin{array}{c}n_{n m ?}{ }^{\circ} \\
\left({ }^{\circ} \mathrm{C}\right)\end{array}$ & $\begin{array}{l}n_{\mathrm{n}} \\
\left({ }^{\circ} \mathrm{C}\right)\end{array}$ \\
\hline 1 & 0 & 27,06 & 28,22 & 28,82 \\
\hline 2 & 5 & 60,51 & 36,30 & 29,10 \\
\hline 3 & 10 & 61,47 & 36,92 & 29,05 \\
\hline 4 & 15 & 60,64 & 36,72 & 29,26 \\
\hline 5 & 20 & 60,58 & 37,12 & 29,19 \\
\hline 6 & 25 & 62,09 & 37,71 & 29,32 \\
\hline 7 & 30 & 61,36 & 37,45 & 29,33 \\
\hline 8 & 35 & 60,62 & 37,12 & 29,35 \\
\hline 9 & 40 & 61,87 & 38,08 & 29,38 \\
\hline 10 & 45 & 62,92 & 38,04 & 29,52 \\
\hline 11 & 50 & 62,13 & 37,90 & 29,52 \\
\hline 12 & 55 & 61,40 & 37,90 & 29,62 \\
\hline 13 & 60 & 60,72 & 37,95 & 29,59 \\
\hline 14 & 65 & 62,32 & 38,84 & 29,63 \\
\hline 15 & 70 & 62,13 & 38,45 & 29,65 \\
\hline 16 & 75 & 61,40 & 38,16 & 29,66 \\
\hline 17 & 80 & 60,62 & 37,68 & 29,60 \\
\hline 18 & 85 & 62,07 & 38,52 & 29,75 \\
\hline 19 & 90 & 62,77 & 38,30 & 2990 \\
\hline 20 & 95 & 62,01 & 37,94 & 29,83 \\
\hline 21 & 100 & 61,28 & 37,94 & 29,65 \\
\hline 22 & 105 & 61,49 & 37,95 & 29,75 \\
\hline 23 & 110 & 60,81 & 37,57 & 29,84 \\
\hline 24 & 115 & 61,67 & 38,21 & 30,00 \\
\hline 25 & 120 & 62,50 & 38,19 & 29,89 \\
\hline
\end{tabular}

Berdasarkan data pada Tabel 1, terlihat bahwa semakin lama proses pemberian kalor pada air di dalam tangki heater menyebabkan temperatur air menjadi naik. Kondisi tersebut dapat dilihat pada temperatur awal menunjukkan $27,06{ }^{\circ} \mathrm{C}$ sedangkan pada tangki Emergency Cooling
Tank (ECT) temperatur menunjukkan 28,82 ${ }^{\circ}$ $\mathrm{C}$ atau pada temperatur kamar. Setelah mengalami pemberian kalor selama satu jam maka temperatur meningkat menjadu $60,72{ }^{\circ} \mathrm{C}$ untuk $T_{H \text { in }}$ dan $29,59{ }^{\circ} \mathrm{C}$ untuk $T_{C}$ pada kolam ECT. Begitu pun halnya untuk temperatur pada $T_{H \text { out }}$ mengalami peningkatan temperatur, pada temperatur awal $T_{H \text { out }}$ setelah diberi kalor dari heater selama satu jam maka temperatur naik menjadi $37,95^{\circ} \mathrm{C}$.

Hal ini menunjukkan bahwa pemberian kalor pada tabung tangki heater akan memanaskan fluida kerja air sehingga terjadi aliran fluida ke atas (buoyancy force) dan kalorpun ikut terbawa sehingga membuat temperatur pada titik $T_{H o u t}$ dan temperatur di Emergency Cooling Tank (ECT) juga naik. Gambar 3 menunjukkan grafik data temperatur pada $, T_{H \text { in }}, T_{H \text { out }}$, dan $T_{C}$ terhadap waktu.

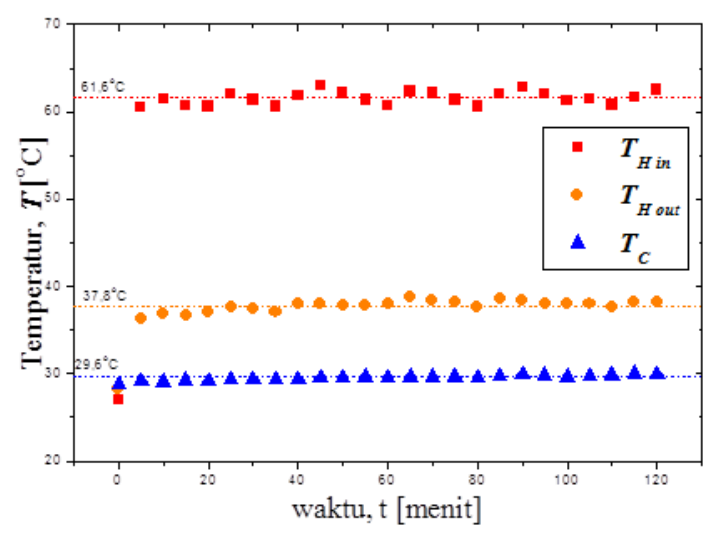

Gambar 3. Grafik temperatur terhadap lama waktu pemanasan

Berdasarkan Gambar 3, terlihat bahwa selama 2 jam temperatur rata-rata di outlet adalah $61,6{ }^{\circ} \mathrm{C}$ dan inlet adalah $37,8^{\circ} \mathrm{C}$. Sedangkan temperatur rata-rata air di ECT adalah $29,6{ }^{\circ} \mathrm{C}$. Kemudian, berdasarkan data tem- 
peratur dari Tabel 1 dilakukan perhitungan jumlah perubahan kalor selama 2 jam untuk ketiga titik pengukuran, diperoleh data perubahan kalor seperti yang ditunjukkan pada Tabel 2.

Tabel 2. Data Kalor $Q_{H \text { in }}, Q_{H \text { out }}$, dan $Q_{C}$

\begin{tabular}{|c|c|c|c|c|}
\hline No. & $\begin{array}{l}\mathrm{t} \\
\text { (menit) }\end{array}$ & $\begin{array}{l}Q_{\text {gin }} \\
(\mathrm{kJ})\end{array}$ & $\begin{array}{l}Q_{x \sim}= \\
(\mathrm{kJ})\end{array}$ & $\begin{array}{l}\underline{Q}_{c} \\
(\mathrm{~kJ})\end{array}$ \\
\hline 1 & 0 & 1779 & 464 & 35 \\
\hline 2 & 5 & 1838 & 549 & 61 \\
\hline 3 & 10 & 1791 & 516 & 130 \\
\hline 4 & 15 & 1748 & 514 & 69 \\
\hline 5 & 20 & 1916 & 600 & 53 \\
\hline 6 & 25 & 1830 & 547 & 111 \\
\hline 7 & 30 & 1793 & 527 & 121 \\
\hline 8 & 35 & 1803 & 547 & 98 \\
\hline 9 & 40 & 1919 & 597 & 152 \\
\hline 10 & 45 & 1872 & 578 & 127 \\
\hline 11 & 50 & 1831 & 594 & 140 \\
\hline 12 & 55 & 1797 & 572 & 165 \\
\hline 13 & 60 & 1799 & 627 & 192 \\
\hline 14 & 65 & 1873 & 590 & 132 \\
\hline 15 & 70 & 1832 & 606 & 183 \\
\hline 16 & 75 & 1793 & 564 & 142 \\
\hline 17 & 80 & 1786 & 564 & 156 \\
\hline 18 & 85 & 1908 & 603 & 193 \\
\hline 19 & 90 & 1865 & 570 & 201 \\
\hline 20 & 95 & 1826 & 577 & 157 \\
\hline 21 & 100 & 1877 & 577 & 173 \\
\hline 22 & 105 & 1804 & 579 & 172 \\
\hline 23 & 110 & 1768 & 578 & 224 \\
\hline 24 & 115 & 1897 & 599 & 217 \\
\hline 25 & 120 & 1779 & 464 & 355 \\
\hline
\end{tabular}

Semakin lama pemberian kalor atau proses pemanasan yang terjadi pada tabung tangki heater maka besar energi kalor $(Q)$ oleh heater juga akan bertambah, dapat dilihat pada menit ke 5, dimana $Q_{H}$ in menunjukkan 1779 kJ, kemudian setelah satu jam pemanasan kalor yang diberikan heater adalah sebesar $1797 \mathrm{~kJ}$. Sama halnya degan sebelumnya bahwa pemberian kalor pada tabung tangki heater memanaskan fluida air sehingga terjadi aliran naik ke atas dan kalor pun ikut terbawa sehing- ga membuat temperatur pada titik $T_{H}$ out dan temperatur di Emergency Cooling Tank (ECT) menjadi naik yang artinya besar $Q$ pada $Q_{H}$ out dan $Q_{C}$ meningkat. Gambar 4 menunjukkan grafik perubahan kalor pada tiga titik pengukuran selama 2 jam.

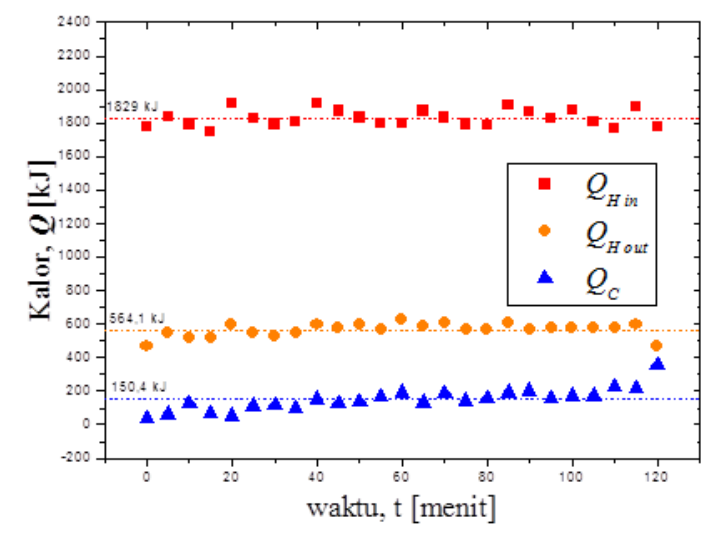

Gambar 4. Grafik kalor terhadap lama waktu pemanasan

Terlihat berdasarkan Gambar 4, bahwa ratarata kalor secara berturut-turut pada inlet dan outlet heater tank adalah 564,1 kJ dan 1829 kJ. Sedangkan kalor di ECT sebesar 150,4 kJ.

Selama dua jam pemberiaan kalor oleh heater tersebut dengan spesifikasi heater yang dipakai dalam percobaan maka secara analitik dan eksperimen yang ada perubahan temperatur tabung tangki heater sebesar $35,57^{\circ} \mathrm{C}$ dan pada kolam ECT sebesar $0,07^{\circ} \mathrm{C}$. Artinya bahwa pemberian temperatur rata-rata $61,6{ }^{\circ} \mathrm{C}$ selama dua jam pemanasan tidak memberikan pengaruh besar terhadap perubahan temperatur di kolam ECT dengan besar perubahan temperaturnya sangat kecil. Sehingga dapat disimpulkan tidak terjadi proses penguapan atau berkurangnya kadar air, meskipun proses aliran sirkulasi alam terjadi. Dimana, sama se- 
sekali tidak terjadi proses evaporasi pada kolam ECT, karena kalor yang diperlukan untuk menguap secara perhitungan estimasi adalah 126931 kJ, sedangkan kalor yang berada pada kolam ECT, rata-rata hanya 150,4 kJ. Kalor yang sampai ke kolam ECT sangat kecil sekali sehingga tidak mampu menguapkan air pada kolam tersebut dan dapat dilihat dari rata-rata temperatur air di ECT sebesar $29,6{ }^{\circ} \mathrm{C}$.

Kalor yang diberikan heater sekitar $721000 \mathrm{~kJ}$ sedangkan kalor rata-rata yang diterima tabung tangki air heater hanya sekitar 1264,9 kJ dan besarnya kalor yang diterima kolam ECT hanya 150, $4 \mathrm{~kJ}$. Hal ini terjadi disebabkan karena beberapa hal terutama heat loss, masih adanya gelembung udara masuk yang seharusnya divakum terlebih dahulu.

\section{KESIMPULAN}

Berdasarkan hasil eksperimen menggunakan Untai Pre-FASSIP-02, telah terlihat aliran sirkulasi alam. Kondisi ini ditentukan berdasarkan pergerakan gelembung kecil selama pemanasan berlangsungd an adanya beda temperatur antara bagian heater tank dan ECT. Kebutuhan kalor untuk memanaskan air di kolam ECT berdasarkan perhitungan volume air yang ada adalah $721000 \mathrm{~kJ}$, sementara dalam eksperimen hanya mencapai 150,4 kJ. Sehingga, tidak ada volume air yang berkurang melalui proses evaporasi. Artinya perubahan kalor di dalam untai yang terjadi cukup kecil dan rugi kalor yang terjadi besar, menyebakan kenaikan temperatur air di ECT tidak akan mencapai titik didihnya.

\section{UCAPAN TERIMA KASIH}

Ucapan terimakasih tak terhingga kepada Kepala PTKRN BATAN, Dr. Geni Rina Sunaryo, MSc. atas izin pelaksanaan Kerja Praktek di PTKRN BATAN, juga kepada staf teknis di Lab. Termohidrolika Eksperimental BPFKR PTKRN BATAN atas bantuannya selama ini. Penulis mengucapkan terimakasih kepada anggaran KEMENRISTEKDIKTI Program INSINAS Riset Pratama Kemitraan antara PTKRN BATAN-FTUI dengan nomor kontrak 02/INS-2/PPK/E/E4/2017.

\section{DAFTAR PUSTAKA}

1. A.F. Wibisono, A. Yoonhan, W. C. Williams, A. Yacine, J. I. Lee, Nuclear Engineering and Design 262, pp. $390-$ 403 (2013).

2. M. Juarsa, J.H. Purba, M. H. Kusuma, T. Setiadipura, S. Widodo, Atom 40 (3), 141-147 (2014).

3. M. Restiya., M. Juarsa, K. Santosa, Joko Prasetio W, Karakterisasi Flowmeter Untuk Laju Aliran Rendah Pada Sirkulasi Alami Di Untai FASSIP-01, Seminar Nasional Sains dan Teknologi, UMJ, pp. 2460 - 8416, 2016.

4. M. Noufal, Giarno, Joko Prasetio W, D. Haryanto., M. Juarsa, Analisis Unjuk Kerja Pemanas dan Pendingin Di Untai Fasilitas Simulasi Sistem Pasif, Sigma Epsilon. Vol. 19. No. 2. pp. 92-101, 2015.

5. M. Juarsa, A. R. Antariksawan, M. H. Kusuma, D. Haryanto, Nandy Putra, Estimation of Natural Circulation Flow 
Based on Temperature in the FASSIP-02

Large-Scale Test Loop Facility, The 2nd

International Tropical Renewable Energy

Conference (i-TREC) 2017, Bali-

Indonesia 3-4 October 2017. (published

in IOP Conf. Series: Earth and Environmental Science 105 (2017))

6. A. R. Antariksawan, S. Widodo, M. Juarsa, D. Haryanto, M. H. Kusuma, Nandy Putra, Numerical study on natural circulation characteristics in FASSIP-02 experimental facility using RELAP5 code, The 2nd International Tropical Renewable Energy, Bali-Indonesia 3-4 October 2017 (published in IOP Conf. Series: Earth and Environmental Science 105 (2017)) 